\title{
Strong convergence theorems for modifying Halpern-Mann iterations for a quasi- $\phi$-asymptotically nonexpansive multi-valued mapping in Banach spaces
}

Yi Li and Hong Bo Liu*

*Correspondence:

liuhongbo@swust.edu.cn School of Science, Southwest University of Science and Technology, Mianyang, Sichuan 621010, P.R. China

\begin{abstract}
The purpose of this paper is to introduce modifying Halpern-Mann's iterations sequence for a quasi- $\phi$-asymptotically nonexpansive multi-valued mapping. Under suitable limit conditions, some strong convergence theorems are proved. The results presented in the paper improve and extend the corresponding results of Chang (Appl. Math. Comput. 218:6489-6497, 2012).

MSC: 47J05; 47H09; 49J25
\end{abstract}

Keywords: multi-valued mapping; quasi- $\phi$-asymptotically nonexpansive; fixed point; iterative sequence

\section{Introduction}

Throughout this paper, we denote by $N$ and $R$ the sets of positive integers and real numbers, respectively. Let $D$ be a nonempty closed subset of a real Banach space $X$. A mapping $T: D \rightarrow D$ is said to be nonexpansive if $\|T x-T y\| \leq\|x-y\|$ for all $x, y \in D$. Let $N(D)$ and $C B(D)$ denote the families of nonempty subsets and nonempty closed bounded subsets of $D$, respectively. The Hausdorff metric on $C B(D)$ is defined by

$$
H\left(A_{1}, A_{2}\right)=\max \left\{\sup _{x \in A_{1}} d\left(x, A_{2}\right), \sup _{y \in A_{2}} d\left(y, A_{1}\right)\right\}
$$

for $A_{1}, A_{2} \in C B(D)$, where $d\left(x, A_{1}\right)=\inf \left\{\|x-y\|, y \in A_{1}\right\}$. The multi-valued mapping $T$ : $D \rightarrow C B(D)$ is called nonexpansive if $H(T x, T y) \leq\|x-y\|$ for all $x, y \in D$. An element $p \in D$ is called a fixed point of $T: D \rightarrow N(D)$ if $p \in T(p)$. The set of fixed points of $T$ is represented by $F(T)$.

In the sequel, let $S(X)=\{x \in X:\|x\|=1\}$. A Banach space $X$ is said to be strictly convex if $\left\|\frac{x+y}{2}\right\| \leq 1$ for all $x, y \in S(X)$ and $x \neq y$. A Banach space is said to be uniformly convex if $\lim _{n \rightarrow \infty}\left\|x_{n}-y_{n}\right\|=0$ for any two sequences $\left\{x_{n}\right\},\left\{y_{n}\right\} \subset S(X)$ and $\lim _{n \rightarrow \infty}\left\|\frac{x_{n}+y_{n}}{2}\right\|=0$. The norm of the Banach space $X$ is said to be Gâteaux differentiable if for each $x, y \in S(X)$, the limit

$$
\lim _{t \rightarrow 0} \frac{\|x+t y\|-\|x\|}{t}
$$


exists. In this case, $X$ is said to be smooth. The norm of the Banach space $X$ is said to be Fréchet differentiable if for each $x \in S(X)$, the limit (1.1) is attained uniformly for $y \in S(x)$, and the norm is uniformly Fréchet differentiable if the limit (1.1) is attained uniformly for $x, y \in S(X)$. In this case, $X$ is said to be uniformly smooth.

Remark 1.1 Let $X$ be a real Banach space with dual $X^{*}$. We denote by $J$ the normalized duality mapping from $X$ to $2^{X^{*}}$, which is defined by

$$
J(x)=\left\{x^{*} \in X^{*}:\left\langle x, x^{*}\right\rangle=\|x\|^{2}=\left\|x^{*}\right\|^{2}\right\}, \quad x \in X,
$$

where $\langle\cdot, \cdot\rangle$ denotes the generalized duality pairing.

The following basic properties of the normalized duality mapping $J$ in a Banach space $X$ can be found in Cioranescu [1].

(1) $X\left(X^{*}\right.$, resp. $)$ is uniformly convex if and only if $X^{*}(X$, resp. $)$ is uniformly smooth;

(2) If $X$ is smooth, then $J$ is single-valued and norm-to-weak* continuous;

(3) If $X$ is reflexive, then $J$ is onto;

(4) If $X$ is strictly convex, then $J x \cap J y \neq \Phi$ for all $x, y \in X$;

(5) If $X$ has a Fréchet differentiable norm, then $J$ is norm-to-norm continuous;

(6) If $X$ is uniformly smooth, then $J$ is uniformly norm-to-norm continuous on each bounded subset of $X$;

(7) Each uniformly convex Banach space $X$ has the Kadec-Klee property, i.e., for any sequence $\left\{x_{n}\right\} \subset X$, if $x_{n} \rightarrow x \in X$ and $\left\|x_{n}\right\| \rightarrow\|x\|$, then $x_{n} \rightarrow x \in X$;

(8) If $X$ is a reflexive and strictly convex Banach space with a strictly convex dual $X^{*}$ and $J^{*}: X^{*} \rightarrow X$ is the normalized duality mapping in $X^{*}$, then $J^{-1}=J^{*}, J J^{*}=I_{x^{*}}$ and $J^{*} J=I_{x}$.

Next we assume that $X$ is a smooth, strictly convex, and reflexive Banach space and $D$ is a nonempty closed convex subset of $X$. In the sequel, we always use $\phi: X \times X \rightarrow \overline{R^{-}}$to denote the Lyapunov bifunction defined by

$$
\phi(x, y)=\|x\|^{2}-2\langle x, J y\rangle+\|y\|^{2}, \quad x, y \in X .
$$

It is obvious from the definition of the function $\phi$ that

$$
\begin{aligned}
& (\|x\|-\|y\|)^{2} \leq \phi(x, y) \leq(\|x\|+\|y\|)^{2}, \\
& \phi(y, x)=\phi(y, z)+\phi(z, x)+2\langle z-y, J x-J z\rangle, \quad x, y, z \in X,
\end{aligned}
$$

and

$$
\phi\left(x, J^{-1}(\alpha J y+(1-\alpha) J z)\right) \leq \alpha \phi(x, y)+(1-\alpha) \phi(x, z)
$$

for all $\alpha \in[0,1]$ and $x, y, z \in X$.

Following Alber [2], the generalized projection $\Pi_{D}: X \rightarrow D$ is defined by

$$
\Pi_{D} x=\arg \inf _{y \in D} \phi(y, x), \quad \forall x \in X
$$


Remark 1.2 (see [3]) Let $\Pi_{D}$ be the generalized projection from a smooth, reflexive, and strictly convex Banach space $X$ onto a nonempty closed convex subset $D$ of $X$, then $\Pi_{D}$ is closed and quasi- $\phi$-nonexpansive from $X$ onto $D$.

Many problems in nonlinear analysis can be reformulated as a problem of finding a fixed point of a nonexpansive mapping. In 1953, Mann [4] introduced the following iterative sequence $\left\{x_{n}\right\}$ :

$$
x_{n+1}=\alpha_{n} x_{n}+\left(1-\alpha_{n}\right) T x_{n},
$$

where the initial guess $x_{1} \in D$ is arbitrary and $\left\{\alpha_{n}\right\}$ is a real sequence in $[0,1]$. It is known that under appropriate settings the sequence $\left\{x_{n}\right\}$ converges weakly to a fixed point of $T$. However, even in a Hilbert space, the Mann iteration may fail to converge strongly [5]. Some attempts to construct an iteration method guaranteeing the strong convergence have been made. For example, Halpern [6] proposed the following so-called Halpern iteration:

$$
x_{n+1}=\alpha_{n} u+\left(1-\alpha_{n}\right) T x_{n},
$$

where $u, x_{1} \in D$ are arbitrarily given and $\left\{\alpha_{n}\right\}$ is a real sequence in $[0,1]$. Another approach was proposed by Nakajo and Takahashi [7]. They generated a sequence as follows:

$$
\left\{\begin{array}{l}
x_{1} \in X \quad \text { is arbitrary, } \\
y_{n}=\alpha_{n} u+\left(1-\alpha_{n}\right) T x_{n}, \\
C_{n}=\left\{z \in D:\left\|y_{n}-z\right\| \leq\left\|x_{n}-z\right\|\right\}, \\
Q_{n}=\left\{z \in D:\left\langle x_{n}-z, x_{1}-x_{n}\right\rangle \geq 0\right\}, \\
x_{n+1}=P_{C_{n} \cap Q_{n}} x_{1} \quad(n=1,2, \ldots),
\end{array}\right.
$$

where $\left\{\alpha_{n}\right\}$ is a real sequence in $[0,1]$ and $P_{K}$ denotes the metric projection from a Hilbert space $H$ onto a closed convex subset $K$ of $H$. It should be noted here that the iteration above works only in a Hilbert space setting. To extend this iteration to a Banach space, the concepts of relatively nonexpansive mappings and quasi- $\phi$-nonexpansive mappings have been introduced (see [8-11] and [12]).

Inspired by Matsushita and Takahashi, in this paper, we introduce modifying HalpernMann iterations sequence for finding a fixed point of a quasi- $\phi$-nonexpansive mappings multi-valued mapping $T: D \rightarrow C B(D)$ and prove some strong convergence theorems. The results presented in the paper improve and extend the corresponding results in [13] and other.

\section{Preliminaries}

In the sequel, we denote the strong convergence and weak convergence of the sequence $\left\{x_{n}\right\}$ by $x_{n} \rightarrow x$ and $x_{n} \rightarrow x$, respectively.

Lemma 2.1 (see [2]) Let X be a smooth, strictly convex and reflexive Banach space, and let $D$ be a nonempty closed convex subset of $X$. Then the following conclusions hold:

(a) $\phi(x, y)=0$ if and only if $x=y$; 
(b) $\phi\left(x, \Pi_{D} y\right)+\phi\left(\Pi_{D} y, y\right) \leq \phi(x, y), \forall x, y \in D$;

(c) If $x \in X$ and $z \in D$, then $z=\Pi_{D} x \Leftrightarrow\langle z-y$,Jx-Jz $\geq 0, \forall y \in D$.

Remark 2.1 If $H$ is a real Hilbert space, then $\phi(x, y)=\|x-y\|^{2}$ and $\Pi_{D}$ is the metric projection $P_{D}$ of $H$ onto $D$.

Lemma 2.2 (see [13]) Let $X$ be a real uniformly smooth and strictly convex Banach space with the Kadec-Klee property, and let D be a nonempty closed convex subset of X. Let $\left\{x_{n}\right\}$ and $\left\{y_{n}\right\}$ be two sequences in D such that $x_{n} \rightarrow p$ and $\phi\left(x_{n}, y_{n}\right) \rightarrow 0$, where $\phi$ is the function defined by (1.2), then $y_{n} \rightarrow p$.

Definition 2.1 A point $x \in D$ is said to be an asymptotic fixed point of $T: D \rightarrow C B(D)$ if there exists a sequence $\left\{x_{n}\right\} \subset D$ such that $x_{n} \rightarrow x \in X$ and $d\left(x_{n}, T\left(x_{n}\right)\right) \rightarrow 0$. Denote the set of all asymptotic fixed points of $T$ by $\hat{F}(T)$.

Definition 2.2 A multi-valued mapping $T: D \rightarrow C B(D)$ is said to be closed if for any sequence $\left\{x_{n}\right\} \subset D$ with $x_{n} \rightarrow x \in X$ and $d\left(y, T\left(x_{n}\right)\right) \rightarrow 0$, then $d(y, T(x))=0$.

Definition 2.3 (1) A multi-valued mapping $T: D \rightarrow C B(D)$ is said to be relatively nonexpansive if $F(T) \neq \Phi, \hat{F}(T)=F(T)$ and $\phi(p, z) \leq \phi(p, x), \forall x \in D, p \in F(T), z \in T(x)$.

(2) A multi-valued mapping $T: D \rightarrow C B(D)$ is said to be quasi- $\phi$-nonexpansive if $F(T) \neq \Phi$, and $\phi(p, z) \leq \phi(p, x), \forall x \in D, p \in F(T), z \in T x$.

(3) A multi-valued mapping $T: D \rightarrow C B(D)$ is said to be quasi- $\phi$-asymptotically nonexpansive if $F(T) \neq \Phi$ and there exists a real sequence $k_{n} \subset[1,+\infty), k_{n} \rightarrow 1$ such that

$$
\phi\left(p, z_{n}\right) \leq k_{n} \phi(p, x), \quad \forall x \in D, p \in F(T), z_{n} \in T^{n} x
$$

Definition 2.4 A mapping $T: D \rightarrow C B(D)$ is said to be uniformly $L$-Lipschitz continuous if there exists a constant $L>0$ such that $\left\|x_{n}-y_{n}\right\| \leq L\|x-y\|$, where $x, y \in D, x_{n} \in T^{n} x$, $y_{n} \in T^{n} y$.

Next, we present an example of a relatively nonexpansive multi-valued mapping.

Example 2.1 (see [13]) Let $I=[0,1], X=C(I)$ (the Banach space of continuous functions defined on $I$ with the uniform convergence norm $\left.\|f\|_{C}=\sup _{t \in I}|f(t)|\right), D=\{f \in X: f(x) \geq$ $0, x \in I\}$ and let $a, b$ be two constants in $(0,1)$ with $a<b$. Let $T: D \rightarrow N(D)$ be a multivalued mapping defined by

$$
T(f)=\left\{\begin{array}{l}
\{g \in D: a \leq f(x)-g(x) \leq b, \forall x \in I\} \\
\{0\} \quad \text { otherwise }
\end{array}\right.
$$

It is easy to see that $F(T)=\{0\}$, therefore $F(T)$ is nonempty.

From the example in [13], we can see that $T: D \rightarrow N(D)$ is a closed quasi- $\phi$-asymptotically nonexpansive multi-valued mapping.

Remark 2.2 From the definitions, it is obvious that a relatively nonexpansive multi-valued mapping is a quasi- $\phi$-nonexpansive multi-valued mapping, and a quasi- $\phi$-nonexpansive 
multi-valued mapping is a quasi- $\phi$-asymptotically nonexpansive multi-valued mapping, and a quasi- $\phi$-asymptotically nonexpansive multi-valued mapping is a total quasi- $\phi$ asymptotically nonexpansive multi-valued mapping, but the converse is not true.

Lemma 2.3 Let $X$ and $D$ be as in Lemma 2.2. Let $T: D \rightarrow C B(D)$ be a closed and quasi- $\phi$ asymptotically nonexpansive multi-valued mapping with nonnegative real sequences $\left\{k_{n}\right\}$ with $\left\{k_{n}\right\} \subset[1, \infty)$ and $k_{n} \rightarrow 1($ as $n \rightarrow \infty)$, then $F(T)$ is a closed and convex subset of $D$.

Proof Let $\left\{x_{n}\right\}$ be a sequence in $F(T)$ such that $x_{n} \rightarrow x^{*}$. Since $T$ is a quasi- $\phi$-asymptotically nonexpansive multi-valued mapping, we have

$$
\phi\left(x_{n}, z\right) \leq k_{1} \phi\left(x_{n}, x^{*}\right)
$$

for all $z \in T x^{*}$ and for all $n \in N$. Therefore,

$$
\phi\left(x^{*}, z\right)=\lim _{n \rightarrow \infty} \phi\left(x_{n}, z\right) \leq \lim _{n \rightarrow \infty} k_{1} \phi\left(x_{n}, x^{*}\right)=k_{1} \phi\left(x^{*}, x^{*}\right)=0 .
$$

By Lemma 2.1(a), we obtain $z=x^{*}$. Hence, $T x^{*}=\left\{x^{*}\right\}$. So, we have $x^{*} \in F(T)$. This implies $F(T)$ is closed.

Let $p, q \in F(T)$ and $t \in(0,1)$, and put $w=t p+(1-t) q$. Next we prove that $w \in F(T)$. Indeed, in view of the definition of $\phi$, let $z_{n} \in T^{n} w$, we have

$$
\begin{aligned}
\phi\left(w, z_{n}\right) & =\|w\|^{2}-2\left\langle w, J z_{n}\right\rangle+\left\|z_{n}\right\|^{2} \\
& =\|w\|^{2}-2\left\langle t p+(1-t) q, J z_{n}\right\rangle+\left\|z_{n}\right\|^{2} \\
& =\|w\|^{2}+t \phi\left(p, z_{n}\right)+(1-t) \phi\left(q, z_{n}\right)-t\|p\|^{2}-(1-t)\|q\|^{2} .
\end{aligned}
$$

Since

$$
\begin{aligned}
& t \phi\left(p, z_{n}\right)+(1-t) \phi\left(q, z_{n}\right) \\
& \leq t k_{n} \phi(p, w)+(1-t) k_{n} \phi(q, w) \\
&= t\left\{\|p\|^{2}-2\langle p, J w\rangle+\|w\|^{2}+\left(k_{n}-1\right) \phi(p, w)\right\} \\
& \quad+(1-t)\left\{\|q\|^{2}-2\langle q, J w\rangle+\|w\|^{2}+\left(k_{n}-1\right) \phi(q, w)\right\} \\
&= t\|p\|^{2}+(1-t)\|q\|^{2}-\|w\|^{2}+t\left(k_{n}-1\right) \phi(p, w)+(1-t)\left(k_{n}-1\right) \phi(q, w) .
\end{aligned}
$$

Substituting (2.3) into (2.4) and simplifying it, we have

$$
\phi\left(w, z_{n}\right) \leq t\left(k_{n}-1\right) \phi(p, w)+(1-t)\left(k_{n}-1\right) \phi(q, w) \rightarrow 0 \quad(\text { as } n \rightarrow \infty) .
$$

Hence, by Lemma 2.2, we have $z_{n} \rightarrow w$. This implies that $z_{n+1}\left(\in T T^{n} w\right) \rightarrow w$. Since $T$ is closed, we have $w \in T w$, i.e., $w \in F(T)$. This completes the proof of Lemma 2.3.

Lemma 2.4 ([13]) Let $X$ be a uniformly convex Banach space, $r>0$ be a positive number and $B_{r}(0)$ be a closed ball of $X$. Then, for any given sequence $\left\{x_{n}\right\}_{n=1}^{\infty} \subset B_{r}(0)$ and for any given sequence $\left\{x_{n}\right\}_{n=1}^{\infty}$ of positive numbers with $\sum_{n=1}^{\infty} \lambda_{n}=1$, there exists a continuous, 
strictly increasing, and convex function $g:[0,2 r) \rightarrow[0, \infty)$ with $g(0)=0$ such that for any positive integers $i, j$ with $i<j$,

$$
\left\|\sum_{n=1}^{\infty} \lambda_{n} x_{n}\right\|^{2} \leq \sum_{n=1}^{\infty} \lambda_{n}\left\|x_{n}\right\|^{2}-\lambda_{i} \lambda_{j} g\left\|x_{i}-x_{j}\right\|^{2} .
$$

Lemma 2.5 ([14]) Let $X$ be a uniformly convex and smooth Banach space and let $\left\{x_{n}\right\}$ and $\left\{y_{n}\right\}$ be two sequences of $X$ such that $\left\{x_{n}\right\}$ or $\left\{y_{n}\right\}$ is bounded. If $\lim _{n \rightarrow \infty} \phi\left(x_{n}, y_{n}\right)=0$, then $\lim _{n \rightarrow \infty}\left\|x_{n}-y_{n}\right\|=0$.

Let $X$ be a reflexive, strictly convex, and smooth Banach space. The duality mapping $J^{*}$ from $X^{*}$ onto $X^{* *}=X$ coincides with the inverse of the duality mapping $J$ from $E$ onto $E^{*}$. We make use the following mapping $v: X \times X^{*} \rightarrow R$ studied in Alber [2]:

$$
v\left(x, x^{*}\right)=\|x\|^{2}-2\left\langle x, x^{*}\right\rangle+\left\|x^{*}\right\|^{2}
$$

for all $x \in X, x^{*} \in X^{*}$. Obviously, $v\left(x, x^{*}\right)=\phi\left(x, J^{-1} x^{*}\right)$.

Lemma 2.6 ([15]) Let $X$ be a reflexive, strictly convex, and smooth Banach space, and let $v$ as in (2.6). Then

$$
v\left(x, x^{*}\right)+2\left(J^{-1} x^{*}-x, y^{*}\right) \leq v\left(x, x^{*}+y^{*}\right)
$$

for all $x \in X, x^{*}, y^{*} \in X^{*}$.

Lemma 2.7 ([16]) Assume that $\left\{\alpha_{n}\right\}$ is a sequence of nonnegative real numbers such that

$$
\alpha_{n+1} \leq\left(1-\gamma_{n}\right) \alpha_{n}+\gamma_{n} \delta_{n}
$$

where $\left\{\gamma_{n}\right\}$ is a sequence in $(0,1)$ and $\left\{\delta_{n}\right\}$ is a sequence such that

(a) $\lim _{n \rightarrow \infty} \gamma_{n}=0, \sum_{n=1}^{\infty} \gamma_{n}=\infty$;

(b) $\lim \sup _{n \rightarrow \infty} \delta_{n} \leq 0$.

Then $\lim _{n \rightarrow \infty} \alpha_{n}=0$.

Lemma 2.8 ([17]) Let $\left\{\alpha_{n}\right\}$ be a sequence of real numbers such that there exists a subsequence $\left\{n_{i}\right\}$ of $\{n\}$ such that $\alpha_{n_{i}} \leq \alpha_{n_{i}+1}$ for all $i \in N$. Then there exists a nondecreasing $\left\{m_{k}\right\} \subset N$ such that $m_{k} \rightarrow \infty$ and the following properties are satisfied for all (sufficiently large) numbers sequence $k \subset N$ :

$$
\alpha_{m_{k}} \leq \alpha_{m_{k}+1} \text { and } \quad \alpha_{k} \leq \alpha_{m_{k}+1} \text {. }
$$

In fact, $m_{k}=\max \left\{j \leq k: \alpha_{j} \leq \alpha_{j+1}\right\}$.

\section{Main results}

Theorem 3.1 Let $X$ be a real uniformly smooth and strictly convex Banach space with the Kadec-Klee property, let $D$ be a nonempty closed convex subset of $X$, and let $T: D \rightarrow C B(D)$ be a closed and uniformly L-Lipschitz continuous quasi- $\phi$-asymptotically nonexpansive 
multi-valued mapping with nonnegative real sequences $\left\{k_{n}\right\} \subset[0,+\infty), k_{n} \rightarrow 1($ as $n \rightarrow \infty)$ such that condition (2.1) and $\prod_{n=1}^{\infty} k_{n}<+\infty$. Let $\left\{\alpha_{n}\right\}$ and $\left\{\beta_{n}\right\}$ be two sequences in $(0,1)$ satisfying

(R1) $\lim _{n \rightarrow \infty} \alpha_{n}=0$ and $\lim _{n \rightarrow \infty} \frac{k_{n}-1}{\alpha_{n}}=0$;

(R2) $\sum_{n=1}^{\infty} \alpha_{n}=\infty$;

(R3) $0<\liminf _{n \rightarrow \infty} \beta_{n} \leq \lim \sup _{n \rightarrow \infty} \beta_{n}<1$.

If $\left\{x_{n}\right\}$ is the sequence generated by

$$
x_{n+1}=\Pi_{D} J^{-1}\left[\alpha_{n} J x_{1}+\left(1-\alpha_{n}\right)\left(\beta_{n} J x_{n}+\left(1-\beta_{n}\right) J z_{n}\right)\right], \quad z_{n} \in T^{n} x_{n},
$$

where $x_{1} \in X$ is arbitrary, $F(T)$ is the fixed point set of $T$, and $\Pi_{D}$ is the generalized projection of $X$ onto D. If $I-T$ is demi-closed at zero and $F(T) \neq \Phi$, then $\lim _{n \rightarrow \infty} x_{n}=\Pi_{F(T)} x_{1}$.

Remark 3.1 We can present an example of $\left\{k_{n}\right\}$ satisfying the conditions $\left\{k_{n}\right\} \subset[0,+\infty)$, $k_{n} \rightarrow 1(\operatorname{as} n \rightarrow \infty)$ and $\prod_{n=1}^{\infty} k_{n}<+\infty$. For instance, if $k_{n}=1+\frac{1}{2^{2 n-1}}$, then $\prod_{n=1}^{\infty} k_{n}=2<+\infty$.

Proof First, we prove that $\left\{x_{n}\right\}$ is a bounded sequence in $D$.

Let $p \in F(T)$ and $y_{n}=J^{-1}\left[\beta_{n} J x_{n}+\left(1-\beta_{n}\right) J z_{n}\right]$ for any $n \in N$. Then

$$
x_{n+1}=\Pi_{D} J^{-1}\left[\alpha_{n} J x_{1}+\left(1-\alpha_{n}\right) J y_{n}\right]
$$

for any $n \in N$. Using (2.1) and (1.5), we have

$$
\begin{aligned}
\phi\left(p, y_{n}\right) & =\phi\left(p, J^{-1}\left[\beta_{n} J x_{n}+\left(1-\beta_{n}\right) J z_{n}\right]\right) \\
& \leq \beta_{n} \phi\left(p, x_{n}\right)+\left(1-\beta_{n}\right) \phi\left(p, z_{n}\right) \\
& \leq \beta_{n} \phi\left(p, x_{n}\right)+\left(1-\beta_{n}\right) k_{n} \phi\left(p, x_{n}\right) \\
& \leq k_{n} \phi\left(p, x_{n}\right),
\end{aligned}
$$

and

$$
\begin{aligned}
\phi\left(p, x_{n+1}\right) & =\phi\left(p, \Pi_{D} J^{-1}\left[\alpha_{n} J x_{1}+\left(1-\alpha_{n}\right) J y_{n}\right]\right) \\
& \leq \phi\left(p, J^{-1}\left[\alpha_{n} J x_{1}+\left(1-\alpha_{n}\right) J y_{n}\right]\right) \\
& \leq \alpha_{n} \phi\left(p, x_{1}\right)+\left(1-\alpha_{n}\right) \phi\left(p, y_{n}\right) \\
& \leq \alpha_{n} \phi\left(p, x_{1}\right)+\left(1-\alpha_{n}\right) k_{n} \phi\left(p, x_{n}\right) \\
& \leq \max \left\{\phi\left(p, x_{1}\right), k_{n} \phi\left(p, x_{n}\right)\right\} \\
& \leq \max \left\{\phi\left(p, x_{1}\right), k_{n} k_{n-1} \phi\left(p, x_{n-1}\right)\right\} .
\end{aligned}
$$

By induction, we have

$$
\phi\left(p, x_{n+1}\right) \leq k_{n} k_{n-1} \cdots k_{1} \phi\left(p, x_{1}\right) .
$$

Since $\lim _{n \rightarrow \infty} k_{n}=1$ and $\prod_{n=1}^{\infty} k_{n}<+\infty$, then $k_{n} k_{n-1} \cdots k_{1}$ is bounded, and we get $\phi\left(p, x_{n+1}\right)$ is bounded. This implies that $\left\{x_{n}\right\}$ is bounded, so is $\left\{z_{n}\right\}$. 
Next, let $g:[0,2 r] \rightarrow[0, \infty)$ be a function satisfying the properties of Lemma 2.5, where $r=\sup \left\{\left\|x_{1}\right\|,\left\|x_{n}\right\|,\left\|z_{n}\right\|\right\}$. Put $p=\Pi_{F(T)} x_{1}$ and $\left.y_{n}=J^{-1}\left(\beta_{n} J x_{n}+\left(1-\beta_{n}\right)\right) z_{n}\right)$. Then

$$
\begin{aligned}
\phi\left(p, y_{n}\right) & =\phi\left(p, J^{-1}\left(\beta_{n} J x_{n}+\left(1-\beta_{n}\right) J z_{n}\right)\right) \\
& \leq \beta_{n} \phi\left(p, x_{n}\right)+\left(1-\beta_{n}\right) k_{n} \phi\left(p, x_{n}\right)-\beta_{n}\left(1-\beta_{n}\right) g\left(\left\|J x_{n}-J z_{n}\right\|\right) \\
& \leq k_{n} \phi\left(p, x_{n}\right)-\beta_{n}\left(1-\beta_{n}\right) g\left(\left\|J x_{n}-J z_{n}\right\|\right),
\end{aligned}
$$

and

$$
\begin{aligned}
\phi\left(p, x_{n+1}\right)= & \phi\left(p, \Pi_{D} J^{-1}\left[\alpha_{n} J x_{1}+\left(1-\alpha_{n}\right) J y_{n}\right]\right) \\
\leq & \phi\left(p, J^{-1}\left[\alpha_{n} J x_{1}+\left(1-\alpha_{n}\right) J y_{n}\right]\right) \\
\leq & \alpha_{n} \phi\left(p, x_{1}\right)+\left(1-\alpha_{n}\right) \phi\left(p, y_{n}\right) \\
\leq & \alpha_{n} \phi\left(p, x_{1}\right)+\left(1-\alpha_{n}\right)\left[k_{n} \phi\left(p, x_{n}\right)-\beta_{n}\left(1-\beta_{n}\right) g\left(\left\|J x_{n}-J z_{n}\right\|\right)\right] \\
\leq & \alpha_{n} k_{n}\left(\phi\left(p, x_{1}\right)-\phi\left(p, x_{n}\right)\right)+\left(k_{n}-1\right) \phi\left(p, x_{n}\right)+\phi\left(p, x_{n}\right) \\
& -\left(1-\alpha_{n}\right) \beta_{n}\left(1-\beta_{n}\right) g\left(\left\|J x_{n}-J z_{n}\right\|\right) .
\end{aligned}
$$

Letting

$$
M=\sup _{n \in N}\left\{\left|k_{n}\left(\phi\left(p, x_{1}\right)-\phi\left(p, x_{n}\right)\right)+\frac{k_{n}-1}{\alpha_{n}} \phi\left(p, x_{n}\right)\right|+\beta_{n}\left(1-\beta_{n}\right) g\left(\left\|J x_{n}-J z_{n}\right\|\right)\right\},
$$

by (3.2), we have

$$
\beta_{n}\left(1-\beta_{n}\right) g\left(\left\|J x_{n}-J z_{n}\right\|\right) \leq \phi\left(p, x_{n}\right)-\phi\left(p, x_{n+1}\right)+\alpha_{n} M .
$$

Let $u_{n}=J^{-1}\left[\alpha_{n} J x_{1}+\left(1-\alpha_{n}\right) J y_{n}\right]$. Then $x_{n+1}=\Pi_{D} u_{n}$ for all $n \in N$. It follows from (2.6) and (2.7) that

$$
\begin{aligned}
\phi\left(p, x_{n+1}\right) \leq & \phi\left(p, J^{-1}\left(\alpha_{n} J x_{1}+\left(1-\alpha_{n}\right) J y_{n}\right)\right)=v\left(p, \alpha_{n} J x_{1}+\left(1-\alpha_{n}\right) J y_{n}\right) \\
\leq & v\left(p, J^{-1}\left(\alpha_{n} J x_{1}+\left(1-\alpha_{n}\right) J y_{n}\right)-\alpha_{n}\left(J x_{1}-J p\right)\right) \\
& -2\left(J^{-1}\left(\alpha_{n} J x_{1}+\left(1-\alpha_{n}\right) J y_{n}\right)-p,-\alpha_{n}\left(J x_{1}-J p\right)\right\rangle \\
= & v\left(p, \alpha_{n} J p+\left(1-\alpha_{n}\right) J y_{n}\right)+2 \alpha_{n}\left\langle u_{n}-p, J x_{1}-J p\right\rangle \\
= & \phi\left(p, J^{-1}\left[\alpha_{n} J p+\left(1-\alpha_{n}\right) J y_{n}\right]\right)+2 \alpha_{n}\left\langle u_{n}-p, J x_{1}-J p\right\rangle \\
\leq & \|p\|^{2}-2\left\langle p, \alpha_{n} J p+\left(1-\alpha_{n}\right) J y_{n}\right\rangle+\left\|\alpha_{n} J p+\left(1-\alpha_{n}\right) J y_{n}\right\|^{2} \\
& +2 \alpha_{n}\left\langle u_{n}-p, J x_{1}-J p\right\rangle \\
\leq & \|p\|^{2}-2 \alpha_{n}\langle p, J p\rangle-2\left(1-\alpha_{n}\right)\left\langle p, y_{n}\right\rangle+\alpha_{n}\|J p\|^{2}+\left(1-\alpha_{n}\right)\left\|J y_{n}\right\|^{2} \\
& +2 \alpha_{n}\left\langle u_{n}-p, J x_{1}-J p\right\rangle \\
= & \alpha_{n} \phi(p, p)+\left(1-\alpha_{n}\right) \phi\left(p, y_{n}\right)+2 \alpha_{n}\left\langle u_{n}-p, J x_{1}-J p\right\rangle \\
\leq & \left(1-\alpha_{n}\right) k_{n} \phi\left(p, x_{n}\right)+2 \alpha_{n}\left\langle u_{n}-p, J x_{1}-J p\right\rangle .
\end{aligned}
$$

The rest of the proof will be divided into two parts. 
Case (1). Suppose that there exists $n_{0}$ such that $\left\{\phi\left(p, x_{n}\right)\right\}_{n_{0}}^{\infty}$ is nonincreasing. In this situation, $\left\{\phi\left(p, x_{n}\right)\right\}_{n_{0}}^{\infty}$ is convergent. Together with (R1), (R3), and (3.2), we obtain

$$
\lim _{n \rightarrow \infty} g\left(\left\|J x_{n}-J z_{n}\right\|\right)=0 .
$$

Therefore, $\lim _{n \rightarrow \infty}\left\|J x_{n}-J z_{n}\right\|=0$ and $\lim _{n \rightarrow \infty}\left\|x_{n}-z_{n}\right\|=0$. Since $d\left(x_{n}, T x_{n}\right) \leq\left\|x_{n}-z_{n}\right\|$, we obtain

$$
\lim _{n \rightarrow \infty} d\left(x_{n}, T x_{n}\right)=0
$$

Then

$$
\begin{aligned}
\phi\left(z_{n}, y_{n}\right) & =\phi\left(z_{n}, J^{-1}\left[\beta_{n} J x_{n}+\left(1-\beta_{n}\right) J z_{n}\right]\right) \\
& \leq \beta_{n} \phi\left(z_{n}, x_{n}\right)+\left(1-\beta_{n}\right) \phi\left(z_{n}, z_{n}\right) \\
& =\beta_{n} \phi\left(z_{n}, x_{n}\right) \rightarrow 0
\end{aligned}
$$

and

$$
\begin{aligned}
\phi\left(y_{n}, u_{n}\right) & =\phi\left(y_{n}, J^{-1}\left[\alpha_{n} J x_{1}+\left(1-\alpha_{n}\right) J y_{n}\right]\right) \\
& \leq \alpha_{n} \phi\left(y_{n}, x_{1}\right)+\left(1-\alpha_{n}\right) \phi\left(y_{n}, y_{n}\right) \\
& =\alpha_{n} \phi\left(y_{n}, x_{1}\right) \rightarrow 0 .
\end{aligned}
$$

From (3.6), (3.7) and Lemma 2.5, we have

$$
\lim _{n \rightarrow \infty}\left\|y_{n}-z_{n}\right\|=0 \quad \text { and } \quad \lim _{n \rightarrow \infty}\left\|y_{n}-u_{n}\right\|=0 .
$$

From (3.4), we have

$$
\lim _{n \rightarrow \infty}\left\|x_{n}-u_{n}\right\|=0
$$

Since $I-T$ is demi-closed at zero, we choose a subsequence $\left\{x_{n_{i}}\right\} \subset\left\{x_{n}\right\}$ such that $x_{n_{i}} \rightarrow$ $p^{*} \in F(T)$. By Lemma 2.2(c), we have

$$
\begin{aligned}
& \limsup _{n \rightarrow \infty}\left\langle u_{n}-p, J x_{1}-J p\right\rangle \\
& \quad=\limsup _{n \rightarrow \infty}\left\langle x_{n}-p, J x_{1}-J p\right\rangle \\
& \quad=\lim _{i \rightarrow \infty}\left\langle x_{n_{i}}-p, J x_{1}-J p\right\rangle=\left\langle p^{*}-p, J x_{1}-J p\right\rangle \leq 0 .
\end{aligned}
$$

Hence the conclusion follows.

Case (2). Suppose that there exists a subsequence $\left\{x_{n_{i}}\right\} \subset\left\{x_{n}\right\}$ such that $\phi\left(p, x_{n_{i}}\right) \leq$ $\phi\left(p, x_{n_{i}+1}\right)$. Then, by Lemma 2.8 , there exists a nondecreasing sequence $\left\{m_{k}\right\} \subset N$, $m_{k} \rightarrow \infty$ such that

$$
\phi\left(p, x_{m_{k}}\right) \leq \phi\left(p, x_{m_{k}+1}\right) \quad \text { and } \quad \phi\left(p, x_{k}\right) \leq \phi\left(p, x_{m_{k}+1}\right) .
$$


This together with (3.2) gives

$$
\beta_{m_{k}}\left(1-\beta_{m_{k}}\right) g\left(\left\|J x_{m_{k}}-J z_{m_{k}}\right\|\right) \leq \phi\left(p, x_{m_{k}}\right)-\phi\left(p, x_{m_{k}+1}\right)+\alpha_{m_{k}} M
$$

for all $k \in N$. Then, by conditions (R1) and (R3),

$$
\lim _{k \rightarrow \infty} g\left(\left\|J x_{m_{k}}-J z_{m_{k}}\right\|\right)=0
$$

By the same argument as Case (1), we get

$$
\lim _{k \rightarrow \infty} \sup \left\langle u_{m_{k}}-p, J x_{1}-J p\right\rangle \leq 0
$$

From (3.3), we get

$$
\phi\left(p, x_{m_{k}+1}\right) \leq\left(1-\alpha_{m_{k}}\right) k_{m_{k}} \phi\left(p, x_{m_{k}}\right)+2 \alpha_{m_{k}}\left\langle u_{m_{k}}-p, J x_{1}-J p\right\rangle
$$

and

$$
\alpha_{m_{k}} k_{m_{k}} \phi\left(p, x_{m_{k}}\right) \leq k_{m_{k}} \phi\left(p, x_{m_{k}}\right)-\phi\left(p, x_{m_{k}+1}\right)+2 \alpha_{m_{k}}\left\langle u_{m_{k}}-p, J x_{1}-J p\right\rangle .
$$

Since $\phi\left(p, x_{m_{k}}\right)-\phi\left(p, x_{m_{k}+1}\right) \leq 0$, we have

$$
\alpha_{m_{k}} k_{m_{k}} \phi\left(p, x_{m_{k}}\right) \leq\left(k_{m_{k}}-1\right) \phi\left(p, x_{m_{k}}\right)+2 \alpha_{m_{k}}\left\langle u_{m_{k}}-p, J x_{1}-J p\right\rangle .
$$

This implies that

$$
\phi\left(p, x_{m_{k}}\right) \leq \frac{k_{m_{k}}-1}{\alpha_{m_{k}}} \phi\left(p, x_{m_{k}}\right)+2\left\langle u_{m_{k}}-p, J x_{1}-J p\right\rangle .
$$

From (3.10) and (R1), we get $\lim _{k \rightarrow \infty} \phi\left(p, x_{m_{k}}\right) \leq 0$ and $x_{m_{k}} \rightarrow p$. This implies that $\lim _{n \rightarrow \infty} x_{n}=p$, which yields that $p=w=\Pi_{F(T)} x_{1}$. Therefore, $x_{n} \rightarrow \Pi_{F(T)} x_{1}$. The proof of Theorem 3.1 is completed.

By Remark 2.2, the following corollaries are obtained.

Corollary 3.1 Let $X$ and $D$ be as in Theorem 3.1, and let $T: D \rightarrow C B(D)$ be a closed and uniformly L-Lipschitz continuous relatively nonexpansive multi-valued mapping. Let $\left\{\alpha_{n}\right\}$ and $\left\{\beta_{n}\right\}$ be two sequences in $(0,1)$ satisfying

(R1) $\lim _{n \rightarrow \infty} \alpha_{n}=0$;

(R2) $\sum_{n=1}^{\infty} \alpha_{n}=\infty$;

(R3) $0<\liminf _{n \rightarrow \infty} \beta_{n} \leq \limsup _{n \rightarrow \infty} \beta_{n}<1$.

Let $\left\{x_{n}\right\}$ be the sequence generated by (3.1), where $F(T)$ is the set of fixed points of $T$, and $\Pi_{D}$ is the generalized projection of $X$ onto $D$, then $\left\{x_{n}\right\}$ converges strongly to $\Pi_{F(T)} x_{1}$.

If we take $\beta_{n}=\beta$, the following result is obtained. 
Corollary 3.2 Let X be a real uniformly smooth and strictly convex Banach space with the Kadec-Klee property, let $D$ be a nonempty closed convex subset of $X$ and let $T: D \rightarrow C B(D)$ be a closed and uniformly L-Lipschitz continuous quasi- $\phi$-asymptotically nonexpansive multi-valued mapping with nonnegative real sequences $\left\{k_{n}\right\} \subset[0,+\infty), k_{n} \rightarrow 1($ as $n \rightarrow \infty)$ satisfying condition (2.1). Let $\left\{\alpha_{n}\right\}$ be a sequence in $(0,1)$ satisfying

(Q1) $\lim _{n \rightarrow \infty} \alpha_{n}=0$ and $\lim _{n \rightarrow \infty} \frac{k_{n}-1}{\alpha_{n}}=0$;

(Q2) $\sum_{n=1}^{\infty} \alpha_{n}=\infty$.

If $\beta \in(0,1)$ and $\left\{x_{n}\right\}$ is the sequence generated by

$$
x_{n+1}=\Pi_{D} J^{-1}\left[\alpha_{n} J x_{1}+\left(1-\alpha_{n}\right) J\left(\beta J x_{n}+(1-\beta) J z_{n}\right)\right], \quad z_{n} \in T^{n} x_{n}
$$

where $x_{1} \in X$ is arbitrary, $F(T)$ is the fixed point set of $T$, and $\Pi_{D}$ is the generalized projection of $X$ onto $D$; if $I-T$ is demi-closed at zero and $F(T)$ is nonempty, then $\lim _{n \rightarrow \infty} x_{n}=$ $\Pi_{F(T)} x_{1}$.

\section{Competing interests}

The authors declare that they have no competing interests.

\section{Authors' contributions}

All authors conceived of the study, participated in its design and coordination, drafted the manuscript, participated in the sequence alignment, and read and approved the final manuscript.

\section{Acknowledgements}

The authors are very grateful to both reviewers for careful reading of this paper and for their comments.

Received: 26 June 2012 Accepted: 30 April 2013 Published: 17 May 2013

\section{References}

1. Cioranescu, I: Geometry of Banach Spaces, Duality Mappings and Nonlinear Problems. Kluwer Academic, Dordrecht (1990)

2. Alber, Yl: Metric and generalized projection operators in banach spaces: properties and applications. In: Kartosator, AG (ed.) Theory and Applications of Nonlinear Operators of Accretive and Monotone Type, pp. 15-50. Dekker, New York (1996)

3. Chang, SS, Chan, CK, Lee, HWJ: Modified Block iterative algorithm for quasi- $\phi$-asymptotically nonexpansive mappings and equilibrium problem in Banach spaces. Appl. Math. Comput. 217, 7520-7530 (2011)

4. Mann, WR: Mean value methods in iteration. Proc. Am. Math. Soc. 4, 506-510 (1953)

5. Genel, A, Lindenstrauss, J: An example concerning fixed points. Isr. J. Math. 22, 81-86 (1975)

6. Halpren, B: Fixed points of nonexpansive maps. Bull. Am. Math. Soc. 73, 957-961 (1967)

7. Nakajo, K, Takahashi, W: Strong convergence theorems for nonexpansive mappings and nonexpansive semigroups J. Math. Anal. Appl. 279, 372-379 (2003)

8. Matsushita, S, Takahashi, W: Weak and strong convergence theorems for relatively nonexpansive mappings in a Banach space. Fixed Point Theory Appl. 2004, 37-47 (2004)

9. Matsushita, S, Takahashi, W: An iterative algorithm for relatively nonexpansive mappings by hybrid method and applications. In: Proceedings of the Third International Conference on Nonlinear Analysis and Convex Analysis, pp. 305-313 (2004)

10. Matsushita, S, Takahashi, W: A strong convergence theorem for relatively nonexpansive mappings in a Banach space. J. Approx. Theory 134, 257-266 (2005)

11. Qin, XL, Cho, YJ, Kang, SM, Zhou, HY: Convergence of a modified Halpern-type iterative algorithm for quasi- $\phi$-nonexpansive mappings. Appl. Math. Lett. 22, 1051-1055 (2009)

12. Wang, ZM, Su, YF, Wang, DX, Dong, YC: A modified Halpern-type iteration algorithm for a family of hemi-relative nonexpansive mappings and systems of equilibrium problems in Banach spaces. J. Comput. Appl. Math. 235, 2364-2371 (2011)

13. Chang, SS: A modified Halpern-type iteration algorithm for totally quasi- $\phi$-asymptotically nonexpansive mappings with applications. Appl. Math. Comput. 218, 6489-6497 (2012)

14. Chang, SS, Kim, JK, Wang, XR: Modified block iterative algorithm for solving convex feasibility problems in Banach spaces. J. Inequal. Appl. 2010, Article ID 869684 (2010)

15. Kohsaka, F, Takahashi, W: Strong convergence of an iterative sequence for maximal monotone operators in a Banach spaces. Abstr. Appl. Anal. 2004, 239-249 (2004)

16. Kohsaka, F, Takahashi, W: Strong convergence of an iterative sequence for maximal monotone operators in a Banach spaces. Abstr. Appl. Anal. 2004, 239-249 (2004)

17. Xu, HK: Another control condition in an iterative method for nonexpansive mappings. Bull. Aust. Math. Soc. 65 109-113(2002) 
doi:10.1186/1687-1812-2013-132

Cite this article as: Li and Liu: Strong convergence theorems for modifying Halpern-Mann iterations for a

quasi- $\phi$-asymptotically nonexpansive multi-valued mapping in Banach spaces. Fixed Point Theory and Applications 2013 2013:132.

Submit your manuscript to a SpringerOpen ${ }^{\circ}$ journal and benefit from:

- Convenient online submission

- Rigorous peer review

- Immediate publication on acceptance

- Open access: articles freely available online

- High visibility within the field

- Retaining the copyright to your article

Submit your next manuscript at $\gg$ springeropen.com 